\title{
Endothelin A receptor blockade improves regression of flow-induced pulmonary vasculopathy in piglets
}

\author{
Olaf Mercier, MD, ${ }^{\mathrm{a}}$ Edouard Sage, $\mathrm{MD},{ }^{\mathrm{b}}$ Mohammed Izziki, PhD, ${ }^{\mathrm{b}}$ Marc Humbert, $\mathrm{MD}, \mathrm{PhD},{ }^{\mathrm{b}}$ \\ Philippe Dartevelle, MD, ${ }^{\mathrm{b}}$ Saadia Eddahibi, $\mathrm{PhD},{ }^{\mathrm{b}}$ and Elie Fadel, $\mathrm{MD}, \mathrm{PhD}^{\mathrm{b}}$
}

Objectives: In patients with chronic thromboembolic pulmonary hypertension, high flow in unobstructed lung regions may induce small-vessel damage responsible for persistent pulmonary hypertension after pulmonary thromboendarterectomy. In piglets, closure of an experimental aortopulmonary shunt reverses the flowinduced vascular lesions and diminishes the elevated levels of messenger RNA (mRNA) expression for endothelin-1 and endothelin receptor A (ETA). We wanted to study the effect of the ETA antagonist TBC 3711 on reversal of flow-induced pulmonary vascular lesions.

Methods: Twenty piglets were studied. In 15 piglets, pulmonary vasculopathy was induced by creating an aortopulmonary shunt. After 5 weeks of shunting, some animals were studied $(n=5)$; others underwent shunt closure for 1 week with $(n=5)$ or without $(n=5)$ TBC3711 treatment. Anti-ETA treatment started 1 week before and ended 1 week after the shunt closure. The controls were sham-operated animals $(\mathrm{n}=5)$.

Results: High blood flow led to medial hypertrophy of the distal pulmonary arteries $(54.9 \% \pm 1.3 \%$ vs $35.3 \% \pm$ $0.9 \% ; P<.0001)$ by stimulating smooth muscle cell proliferation (proliferating cell nuclear antigen) and increased the expression of endothelin-1, ETA or endothelin receptor type A or endothelin receptor A, angiopoietin 1 , and Tie 2 (real-time polymerase chain reaction). One week after shunt closure, gene expression levels were normal and smooth muscle cells showed increased apoptosis (terminal deoxynucleotidyl transferase-mediated dUTP nick end labeling) without proliferation. However, pulmonary artery wall thickness returned to control values only in the group given TBC3711 $(33.2 \% \pm 8 \%$ with and $50.3 \% \pm 1.3 \%$ without; $P<.05)$.

Conclusions: Anti-ETA therapy accelerated the reversal of flow-induced pulmonary arterial disease after flow correction. In patients with chronic thromboembolic pulmonary hypertension and severe distal pulmonary vasculopathy, anti-ETA agents may prove useful for preventing persistent pulmonary hypertension after pulmonary thromboendarterectomy. (J Thorac Cardiovasc Surg 2010;140:677-83)

Chronic thromboembolic pulmonary hypertension (CTEPH) is due to partial obstruction of the pulmonary arterial tree by organized clots, which increase the pulmonary vascular resistance (PVR), leading to progressive pulmonary hypertension $(\mathrm{PH})$ and right heart failure. ${ }^{1}$ The main treatment is pulmonary thromboendarterectomy (PTE), which provides longterm hemodynamic and functional benefits and increases life expectancy. ${ }^{2-5}$ However, PTE is associated with a $10 \%$ mortality rate related chiefly to persistent $\mathrm{PH}$ despite removal of the thrombotic material. ${ }^{2-4}$ Persistent $\mathrm{PH}$ may reflect the existence of lesions in small precapillary vessels that are not accessible to surgery. ${ }^{6}$ Histopathologic studies show microvascular changes similar to those seen in idio-

\footnotetext{
From Inserm U999 a and Laboratoire de Chirurgie Expérimentale UPRES-EA 2705, ${ }^{\text {b }}$ Université Paris XI, Hôpital Marie Lannelongue, Le Plessis-Robinson, France. This work was supported by a grant from Pneumologie Developpement, France. Disclosures: None.

Received for publication Aug 24, 2009; revisions received Dec 6, 2009; accepted for publication Jan 1, 2010.

Address for reprints: Olaf Mercier, MD, Inserm U999, Hôpital Marie Lannelongue, 133 Avenue de la Résistance, 92350 Le Plessis-Robinson, France (E-mail: o.mercier@ ccml.fr).

$0022-5223 / \$ 36.00$

Copyright (c) 2010 by The American Association for Thoracic Surgery

doi:10.1016/j.jtcvs.2010.01.004
}

pathic PH and Eisenmenger syndrome. ${ }^{7-9}$ These distal lesions in the unobstructed territories may contribute to the progression of the hemodynamic abnormalities and symptoms in the absence of further pulmonary embolism. ${ }^{10,11}$

Compared with acute pulmonary embolism, CTEPH with a similar degree of vascular obstruction is associated with far higher PVR values as assessed by lung perfusion scanning. ${ }^{8}$ In patients with CTEPH, the unobstructed territories are chronically exposed to high blood flow owing to cardiac output redistribution. ${ }^{10,12}$ This high blood flow may contribute to increase the PVR, ${ }^{13}$ inasmuch as chronic high flow causes distal arteriopathy with vascular remodeling ${ }^{7,14}$ similar to that found in primary $\mathrm{PH}^{15-19}$ As a result, alterations develop in the distal pulmonary arteries, adding to the PVR increase induced by the proximal occlusion. Greater severity of the microvascular disease is associated with higher PVR values, which in turn predict higher mortality after PTE. ${ }^{6}$ We have developed a piglet model of pulmonary vasculopathy induced by high blood flow to the lungs through an aortopulmonary shunt left open for 5 weeks. There was no chronic pulmonary artery obstruction in our model, which therefore does not provide any information about potential effects of chronically occluded territories on nonoccluded territories. However, our model replicates 


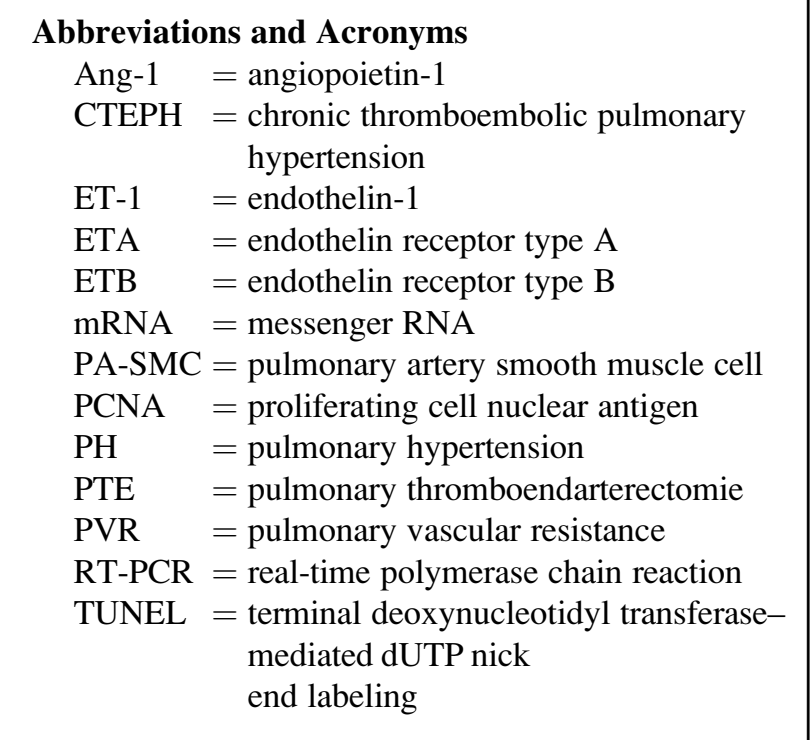

the functional vascular changes seen in the nonoccluded territories of patients with CTEPH. ${ }^{20} \mathrm{We}^{21}$ previously reported that the shunt induced thickening of the media of small pulmonary arteries $(<200 \mu \mathrm{m}$ in diameter) and overexpression of endothelin-1 (ET-1), endothelin receptor type A (ETA), angiopoietin-1 (Ang-1), and Tie2. One week after shunt closure, we found normal expression of mRNAs for ET-1, ETA, Ang-1, and Tie2 and partial reversal of the medial hypertrophy. ${ }^{21}$ These data suggest that ET-1 and ETA may hold promise as therapeutic targets in patients with severe distal microvascular disease in unobstructed territories. Treatments targeting ET-1 have been used in other forms of PH. However, there is no evidence that ET-1 antagonist treatment given before PTE improves postoperative outcomes in patients with severe distal vascular changes.

The objective of this study was to evaluate the effects of the selective ETA antagonist TBC3711 on reversal of flow-induced pulmonary vasculopathy after shunt closure in our piglet model.

\section{MATERIALS AND METHODS}

We studied 20 Large White piglets weighing $21 \pm 3 \mathrm{~kg}$. The study complied with the National Institutes of Health "Guidelines for the Care and Use of Laboratory Animals" and was approved by the institutional committee on animal welfare.

\section{Experimental Design}

Twenty piglets were randomly allocated to 4 groups of 5 . An aortopulmonary shunt was created in 3 groups to increase the blood flow to the pulmonary arteries. After 5 weeks of shunting, the animals in 1 of these groups were humanely killed (high-flow group) and those in the other 2 groups underwent shunt closure and then were humanely killed 1 week later. Of these 2 shunt-closure groups, 1 was untreated and killed 1 week after shunt closure (flow-correction group) and the other was treated with the selective ETA antagonist TBC3711 (flow-correction plus anti-ETA group), which was started 1 week before shunt closure and continued until 1 week after shunt closure, when the animals were killed. The animals in the fourth group were killed 5 weeks after a sham operation consisting in dissection of the pulmonary artery (sham group).

Previous in vitro studies in humans and piglets have established that TBC3711 is a selective ETA antagonist. ${ }^{22,23}$ We used TBC3711 capsules in 2 daily oral doses of $11 \mathrm{mg} \cdot \mathrm{kg}^{-1}$ for 2 weeks. ${ }^{23}$

\section{Surgical Procedures}

An aortopulmonary shunt was created and closed as previously described. $^{21}$

Hemodynamic measurements and lung harvesting. Pulmonary hemodynamic variables, aortic blood flow, pressures, and blood gases were measured as previously described. ${ }^{21}$

Biopsy specimens weighing 300 to $500 \mathrm{mg}$ were taken from the left upper lobe, snap-frozen in liquid nitrogen, and stored at $-70^{\circ} \mathrm{C}$ or fixed in $4 \%$ paraformaldehyde solution.

Light microscopy and morphometry. Fixed lung sections were processed by standard histologic techniques and embedded in paraffin. We sought to identify 30 to 40 arteries measuring less than $200 \mu \mathrm{m}$ in diameter in the lung specimens from each piglet. Media thickness (MT) was calculated as follows: $\% \mathrm{MT}=(\mathrm{ED}-\mathrm{ID} / \mathrm{ED}) \cdot 100$, where $\mathrm{ED}$ is the external diameter and ID the internal diameter.

In situ evaluation of smooth muscle cell death and proliferation and of collagen accumulation. We evaluated the proliferation of pulmonary artery smooth muscle cells (PA-SMCs) by labeling the proliferating cell nuclear antigen (PCNA) ${ }^{21}$ Cells undergoing apoptosis were detected with the ApopTag Red In Situ Apoptosis Detection Kit (Qbiogene, Illkirch, France). To assess collagen accumulation, we deparaffinized paraffin-embedded sections and stained them with Masson trichrome stain.

Real-time quantification by polymerase chain reaction assay (RT-PCR). RT-PCR assays were conducted as previously described. ${ }^{16}$ The primers for ET-1, ETA, and endothelin receptor type B (ETB) were the specific porcine primers previously described by Rondelet and associates. ${ }^{16}$ For Ang-1, Tie2, and 18S RNA, we used primers designed on Primer Express software (Applied Biosystems, Foster City, Calif).

\section{Statistical Analysis}

All results are reported as means \pm standard error of the mean. The Kolmogorov-Smirnov test was used on each variable to determine whether the values were normally distributed. One-way analysis of covariance was performed using the weight of the piglets as the covariate, followed by Fisher's test for between-group comparisons. All statistical analyses were performed with Statview IV software (Abacus Concept, Berkeley, Calif).

\section{RESULTS}

The animals in the 2 flow-correction groups were kept 1 week longer than the animals in the high-flow and sham groups and, accordingly, exhibited higher mean weights when humanely killed $(34 \pm 5 \mathrm{~kg}$ and $40 \pm 8 \mathrm{~kg}$ in the flow-correction groups with and without anti-ETA treatment, respectively, and $25 \pm 3 \mathrm{~kg}$ and $27 \pm 4 \mathrm{~kg}$ in the high-flow and sham groups, respectively).

\section{Effect of the Aortopulmonary Shunt on Hemodynamic Variables}

Compared with the sham-operated animals, animals in the high-flow group had higher values for cardiac output (3.4 \pm $0.4 \mathrm{~L} / \mathrm{min}$ vs $2.1 \pm 0.16 \mathrm{~L} / \mathrm{min}$ ) and mean pulmonary artery 
TABLE 1. Changes in hemodynamic variables

\begin{tabular}{|c|c|c|c|c|}
\hline & Sham & High flow & Flow correction & Flow correction + anti-ETA \\
\hline Weight $(\mathrm{kg})$ & $25 \pm 3$ & $27 \pm 4$ & $41 \pm 7$ & $34 \pm 5$ \\
\hline HR (beats/min) & $95 \pm 5$ & $90 \pm 2$ & $90 \pm 8$ & $90 \pm 16$ \\
\hline $\mathrm{Q}(\mathrm{L} / \mathrm{min})$ & $2.1 \pm 0.16$ & $3.4 \pm 0.4^{*}$ & $2.2 \pm 0.6 \dagger$ & $1.67 \pm 0.2 \dagger$ \\
\hline Indexed $\mathrm{Q}\left(\mathrm{mL} \cdot \min ^{-1} \cdot \mathrm{kg}^{-1}\right)$ & $90 \pm 26$ & $118 \pm 36^{*}$ & $45 \pm 10 \ddagger$ & $49 \pm 14 \ddagger$ \\
\hline mSAP $(\mathrm{mm} \mathrm{Hg})$ & $56 \pm 2$ & $52 \pm 4$ & $50 \pm 4$ & $47.4 \pm 6$ \\
\hline mPAP $(\mathrm{mm} \mathrm{Hg})$ & $10.2 \pm 0.5$ & $15.9 \pm 1.2^{*}$ & $10.1 \pm 2 \dagger$ & $9 \pm 3 \dagger$ \\
\hline
\end{tabular}

$E T A$, endothelin receptor type A; $H R$, heart rate; $Q$, cardiac output; $m S A P$, mean systemic arterial pressure; $m P A P$, mean pulmonary arterial pressure. $* P<.05$ vs sham group. $\dagger P<.05$ vs high-flow group. $\ddagger P<.05$ vs sham and high-flow groups.

pressure $(15.9 \pm 1.2 \mathrm{~mm} \mathrm{Hg}$ vs $10.2 \pm 0.5 \mathrm{~mm} \mathrm{Hg} ; P<.05)$ (Table 1). In both flow-corrected groups, cardiac output and mean pulmonary artery pressure were similar and returned to sham values. Heart rate and mean systemic arterial pressure were similar in all groups.

\section{Pulmonary Vascular Remodeling}

Five weeks after shunt creation (high-flow group), media thickness of pulmonary arteries less than $200 \mu \mathrm{m}$ in diameter was significantly greater than in the sham group $(54.9 \% \pm$ $1.3 \%$ vs $35.3 \% \pm 0.9 \% ; P<.001)$. One week after shunt closure alone (flow-correction group), media thickness was nonsignificantly decreased compared with the high-flow group $(50.3 \% \pm 1.3 \%$ vs $54.9 \% \pm 1.3 \% ; P=.062)$. When anti-ETA treatment was given, media thickness 1 week after shunt closure was not significantly different from the value in the sham group $(33.2 \% \pm 8 \%$ vs $35.3 \%$

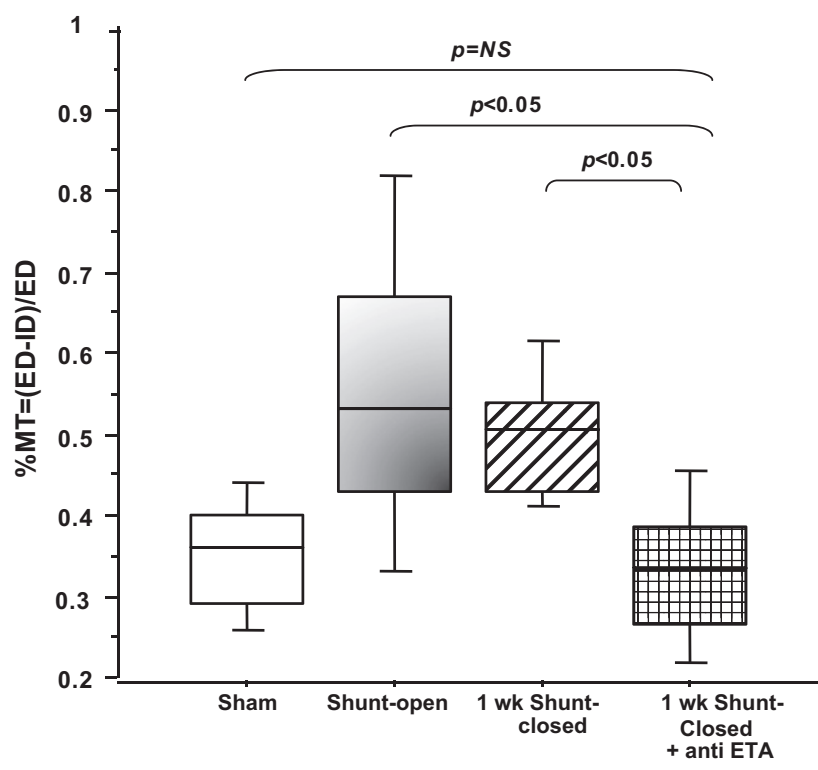

FIGURE 1. Box plot of the percentage of media thickness of small pulmonary arteries $(<200 \mu \mathrm{m})$ assessed by morphometry $(\times 400)$ in the sham group $(35.5 \% \pm 0.9 \%)$, high-flow group $(54.9 \% \pm 1.3 \%)$, flow-correction group $(50.3 \% \pm 1.3 \%)$, and flow-correction plus anti-ETA group $(33.2 \% \pm$ $8 \%$ ). Media thickness returned to sham values 1 week after shunt closure in the group given anti-ETA therapy. $M T$, Media thickness; $E D$, external diameter; $I D$, internal diameter. $\pm 0.9 \% ; P=$ not significant) (Figure 1). One week after shunt closure, media thickness had decreased significantly more in animals that received anti-ETA treatment $(P=.001)$.

PCNA labeling showed PA-SMC proliferation in the distal arteries in the high-flow group $(22.6 \% \pm 14 \%$ vs $6.4 \%$ $\pm 9 \%$ in the sham group; $P<.05$ ), with a return to sham values 1 week after shunt closure. Conversely, the number of apoptotic cells detected by terminal deoxynucleotidyl transferase-mediated dUTP nick end labeling (TUNEL) in pulmonary arterial walls was not significantly different between the high-flow group and the sham group $(6.9 \% \pm$ $5 \%$ vs $9.4 \% \pm 10 \% ; P=$ not significant) but was significantly higher in the flow-correction group than in the sham group $(23.2 \% \pm 16 \%$ vs $9.4 \% \pm 10 \% ; P<.05)$. Flowcorrection plus anti-ETA treatment was associated with decreased PA-SMC proliferation $(5.9 \% \pm 6 \%$ vs $22.6 \%$ $\pm 14 \%$ PCNA-positive cells; $P<.05)$ and with an increase in apoptotic PA-SMCs $(17.7 \% \pm 9 \%$ vs $9.4 \% \pm 10 \%$; $P<.05)$. PCNA and TUNEL labeling were similar in both flow-correction groups. Collagen accumulation around the pulmonary arteries was not different across groups (Figures 2 and 3).

\section{Expression of Genes Involved in the ET-1 and Ang-1 Pathways (Figures 4 and 5)}

Compared with the sham group, the high-flow group had higher mRNA levels for ET-1, ETA, Ang-1, and Tie2; there was no difference for steady-state ETB mRNA.

ETA, Ang-1, and Tie 2 mRNA levels were not significantly different from the sham values in either of the flowcorrection groups. ET-1 expression in the flow-correction group was also similar to the sham value. In the flowcorrection plus anti-ETA group, ET-1 expression was lower than in the high-flow group but higher than in the sham group.

\section{DISCUSSION}

In a model of flow-induced pulmonary vasculopathy induced by 5 weeks of aortopulmonary shunting, the distal arterial medial hypertrophy resulting from smooth muscle cell proliferation and the overexpression of ET-1, ETA, Ang-1, and Tie 2 in the lung parenchyma showed greater improvements 1 week after shunt closure in the animals given a selective ETA antagonist for 2 weeks than in the untreated animals. 

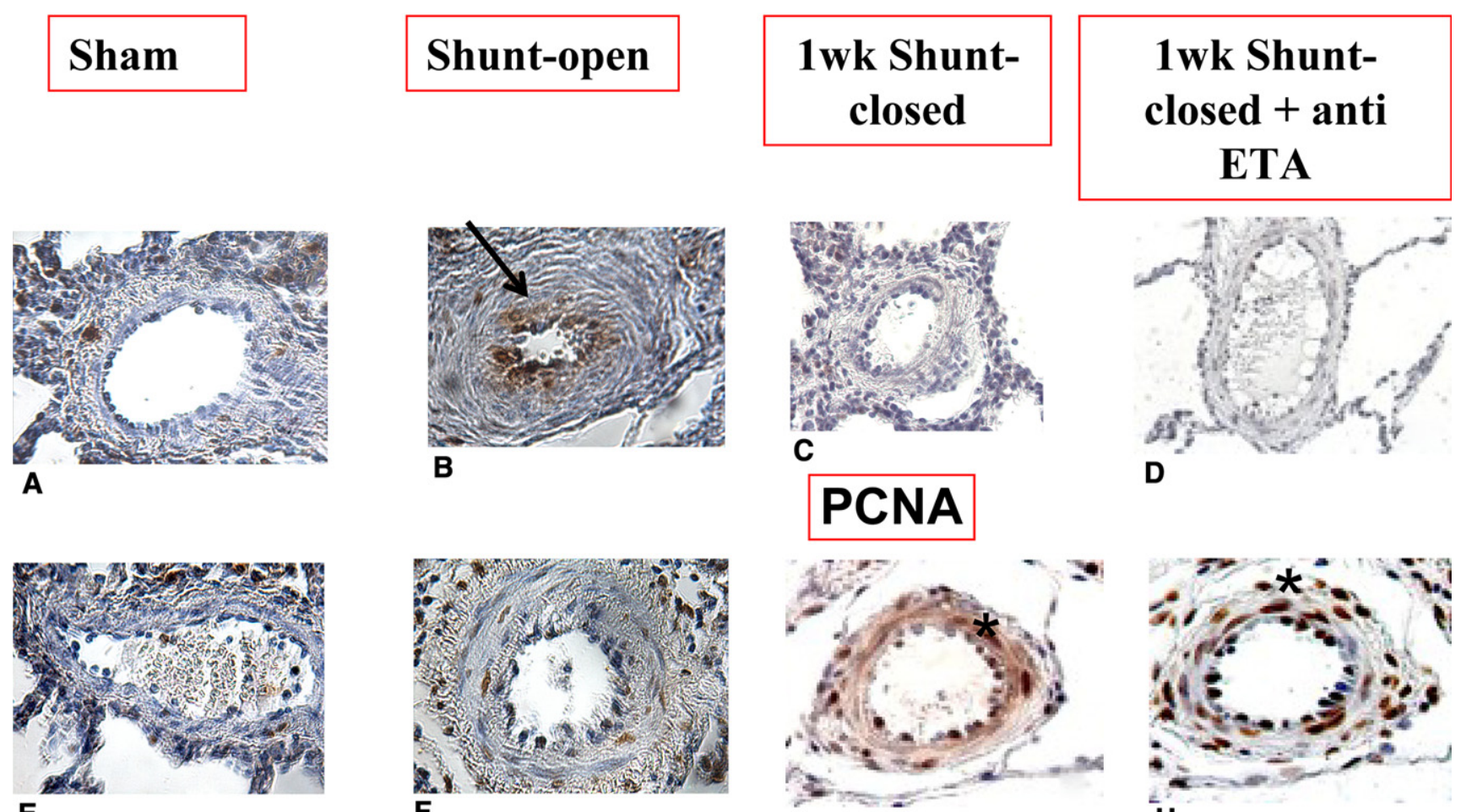

B

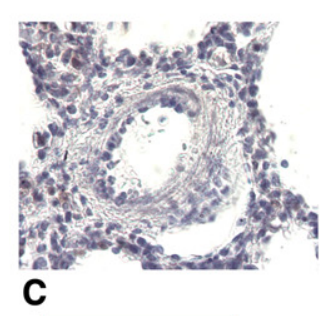

PCNA
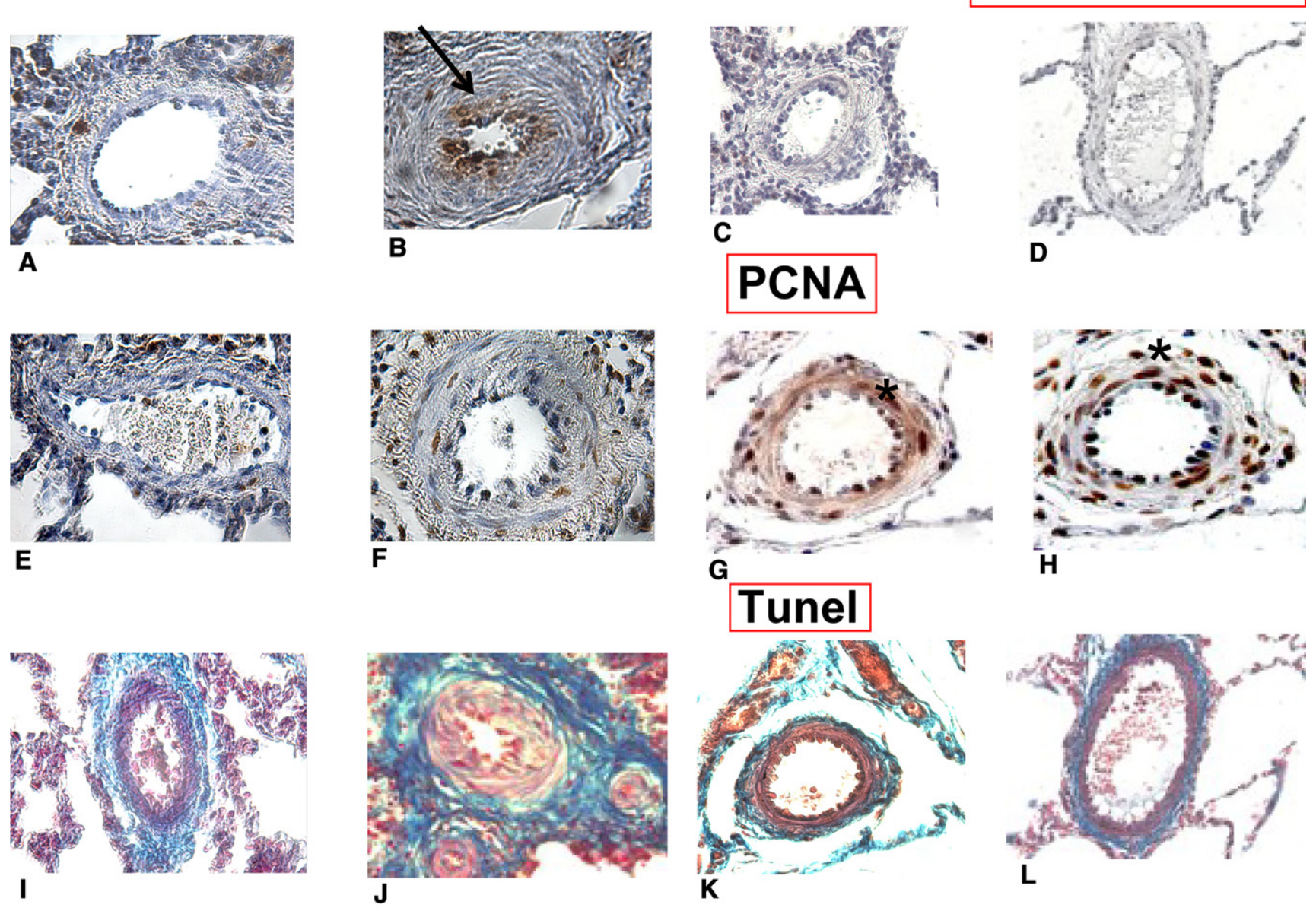

D
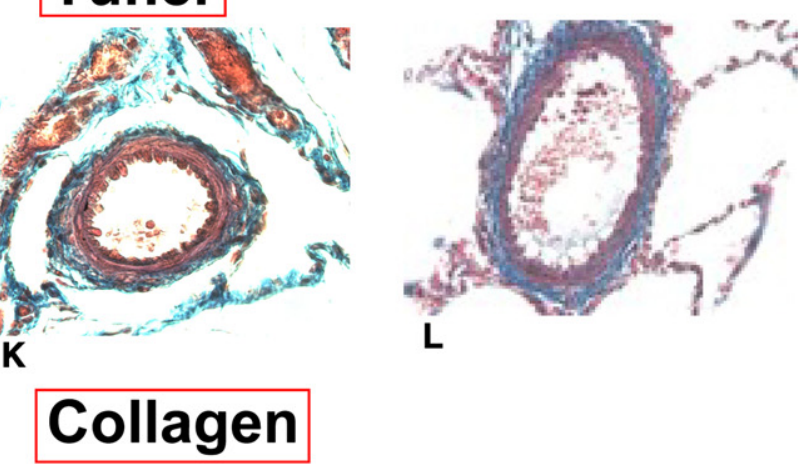

FIGURE 2. Evaluation of in situ proliferation of pulmonary artery smooth muscle cells (PA-SMCs) by PCNA labeling (A, B, C, D) of PA-SMC death by TUNEL (E, F, G, H) and of collagen accumulation by Masson trichrome staining (I, J, K, L) in the high-flow, flow-correction, flow-correction plus anti-ETA, and sham groups $(\times 400)$. Positive cells by TUNEL and PCNA labeling are brown. Collagen is stained blue by Masson's trichrome. Pulmonary artery medial hypertrophy in the high-flow group is related to PA-SMC proliferation (B, arrow) without intravascular collagen accumulation (J). The decrease in media thickness 1 week after shunt closure alone or with anti-ETA was associated with a decrease in PCNA-positive cells (C, D) and with an increase in TUNEL-positive cells (G, H, asterisk). Anti-ETA therapy was started 1 week before shunt closure and the smaller media thickness value in the group given anti-ETA indicates that the treatment was effective in diminishing the medial hypertrophy. TUNEL, Terminal deoxynucleotidyl transferase-mediated dUTP nick end labeling; ETA, endothelin receptor type A; $P C N A$, proliferating cell nuclear antigen.

This finding supports a key role for ET-1 and ETA in the development of flow-induced pulmonary vasculopathy.

After pulmonary embolism, the unobstructed lung territory is exposed to chronic high blood flow owing to redistribution of the cardiac output. ${ }^{10,12}$ In patients with severe CTEPH (defined as very high PVR), extensive distal pulmonary lesions induced by high blood flow may result in failure of PTE to lower the PVR and, therefore, in increased postoperative morbidity and mortality rates. ${ }^{10,12,13}$ In our animal model, ${ }^{21} 5$ weeks of aortopulmonary shunting led to hypertrophy of the distal arterial media related to smooth muscle cell proliferation, as shown by PCNA labeling. We found that the flow-induced distal vasculopathy was associated with overexpression of mRNAs for ET-1, ETA, Ang1 , and Tie2. When we used shunt closure to replicate the effects of PTE on nonoccluded territories, we found that 

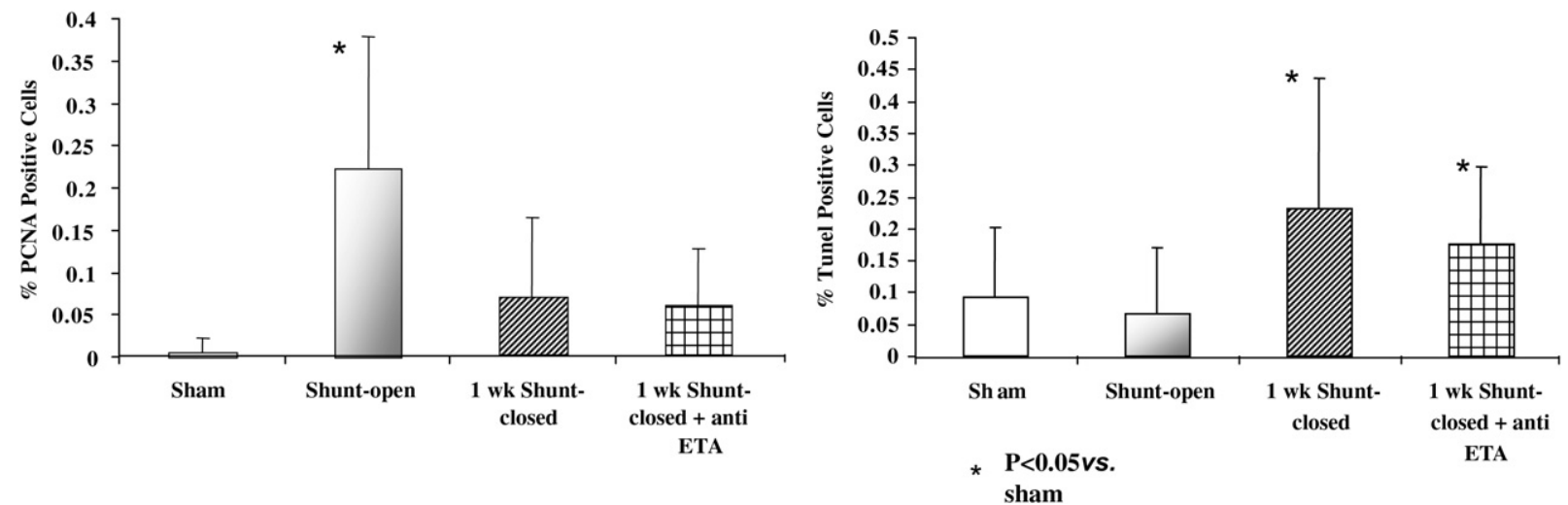

FIGURE 3. Percentage of PCNA and TUNEL-positive cells in the distal pulmonary artery wall in all groups of piglets. PA-SMC proliferation was noted in the high-flow group but was no longer present 1 week after shunt closure. PA-SMC apoptosis was increased 1 week after shunt closure with or without antiETA therapy. TUNEL, Terminal deoxynucleotidyl transferase-mediated dUTP nick end labeling; ETA, endothelin receptor type A; PCNA, proliferating cell nuclear antigen. $P<.05$ vs sham.

the distal vasculopathy improved and the mRNAs for ET-1, ETA, Ang-1, and Tie 2 returned to sham values within 1 week. Reversal of the vasculopathy was associated with a decrease in PA-SMC proliferation and with an increase in PASMC apoptosis. In an earlier study, we $\mathrm{e}^{21}$ examined piglets 5 weeks after shunt closure and found a marked improvement in the distal vascular alterations with no change in the ET-1 pathway but with overexpression of ETB mRNA. We suggested that, in our model, ETB might be involved in controlling ET-1 clearance and, consequently, might contribute to reversal of the flow-induced vasculopathy. This study ${ }^{21}$ showed that increased expression of ET-1 mRNA was associated with the development of distal pulmonary vasculopathy. Indeed, among endogenous vasoconstrictors, ET-1 has one of the strongest and longest lasting effects. Furthermore, ET-1 has been shown to play a pathogenic role in idiopathic $\mathrm{PH}$, which is characterized by distal vascular lesions similar to those induced by high blood flow. We therefore investigated the effect of an ET-1 receptor antagonist on reversal of flow-induced vasculopathy after flow correction. $\mathrm{We}^{21}$ studied a selective ETA antagonist because of the possible beneficial role of the ETB receptor on reversal of flow-induced distal vasculopathy.

Administration of an ETA antagonist exerted a substantial effect on reversal of the flow-induced distal vasculopathy after flow correction. One week after shunt closure, reversal of the medial hypertrophy of distal arteries was complete in the group given the ETA antagonist and incomplete in the untreated group. In both groups, reversal of the medial hypertrophy after flow correction was due to decreased PA-SMC proliferation and increased PA-SMC apoptosis. Thus, medial hypertrophy reversal after flow correction was accelerated by treatment with a selective ETA antagonist.

One week after the shunt closure, normalization of ET-1, ETA, Ang-1, and Tie2 mRNA expressions preceded the normalization of media thickness. This result is consistent with the key role of ET-1 and Ang-1 in distal pulmonary remodeling. ET-1 expression analysis in the group given anti-ETA therapy could be not strictly accurate inasmuch as ET-1 is the therapeutic target. Therefore, we hypothesized that the higher level of ET-1 expression in the group given antiETA therapy could be related to a negative feedback effect.

Over the past decade, several targeted treatments have been used in patients with $\mathrm{PH}$, including prostacyclin analogs, endothelin-receptor antagonists, and phosphodiesterase-5 inhibitors. Marked structural changes in nonoccluded pulmonary arteries have been reported in $\mathrm{CTEPH},{ }^{7}$ and these targeted treatments have been used in patients with inoperable CTEPH. As mortality after pulmonary endarterectomy is increased in patients with high preoperative and postoperative PVR, such treatments are also strongly recommended preoperatively in patients with severe CTEPH. Data on the efficacy of endothelin-receptor antagonist therapy in CTEPH are limited and come mainly from nonrandomized trials. Many studies $^{24-27}$ found encouraging results with the ETA/ETB antagonist bosentan in patients with inoperable CTEPH or persistent PH after PTE. Right heart catheterization values, functional status and tests, and pro-brain natriuretic peptide levels improved significantly with bosentan treatment. In a multicenter randomized trial comprising a 4-month parallel-group comparison of bosentan with a placebo, bosentan therapy significantly improved PVR and cardiac index values. ${ }^{28}$ A study of patients with inoperable CTEPH diagnosed in 2003 or later, that is, after the introduction of targeted therapies, showed an $82 \%$ survival after 1 year and a $70 \%$ survival after 3 years. ${ }^{5}$ Nevertheless, long-term survival is best with PTE, which therefore remains the treatment of choice. ${ }^{5}$ These findings are consistent with a key role for distal pulmonary vasculopathy in patients with CTEPH and therefore with a major place for treatments targeting the endothelin receptors.

Conceivably, endothelin-receptor antagonist therapy might prove useful as a bridge to PTE in patients who 


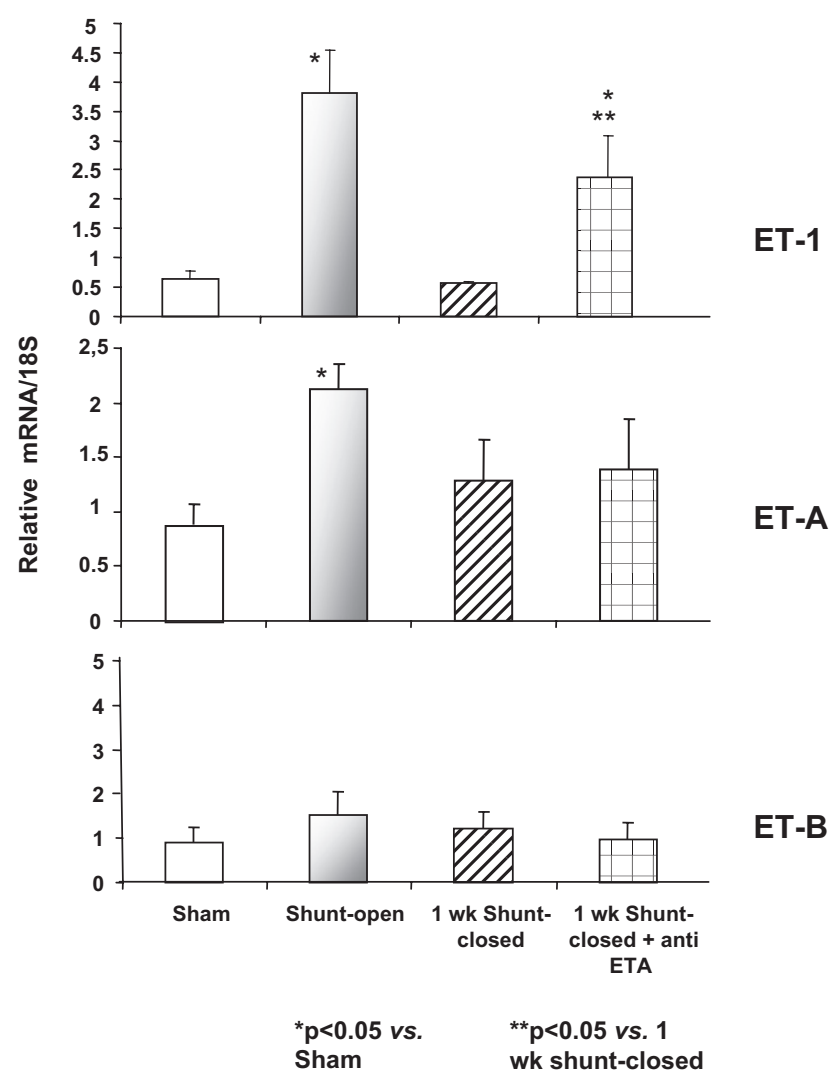

FIGURE 4. Quantification by RT-PCR of the mRNAs for endothelin-1 $(E T-1)$ and its receptors (ETA and ETB) in lung parenchyma. High blood flow in the lungs increased the expression of ET-1 and ETA mRNAs but did not change the steady-state level of ETB mRNA expression. One week after shunt closure, ET-1 and ETA mRNA levels had returned to normal. Except for ET-1, mRNA levels decreased similarly after flow correction with and without anti-ETA therapy. The ET-1 level remained elevated in the anti-ETA group. $* P<.05$ vs sham. ${ }^{*} * P<.05$ vs 1 week shunt-closed.

have a high operative risk with very high PVR values $(>900$ dyn $\cdot \mathrm{s} \cdot \mathrm{cm}^{-5}$ ) and moderate proximal artery occlusion as assessed by pulmonary angiography and thoracic computed tomography. A discrepancy between high PVR values and limited proximal occlusion is indirect evidence of major damage to the distal nonoccluded arterial bed. Our findings suggest that endothelin receptor antagonist therapy started before PTE in patients with high-risk CTEPH may accelerate the postoperative reversal of the flow-induced vasculopathy, thereby decreasing postoperative mortality.

\section{CONCLUSION}

ET-1 and its receptor ETA play a key role in the development of flow-induced pulmonary vasculopathy in the nonoccluded pulmonary arterial bed of patients with CTEPH. Flow correction by aortopulmonary shunt closure to replicate the effects of PTE in patients with CTEPH was followed by rapid normalization of ET-1 expression and incomplete

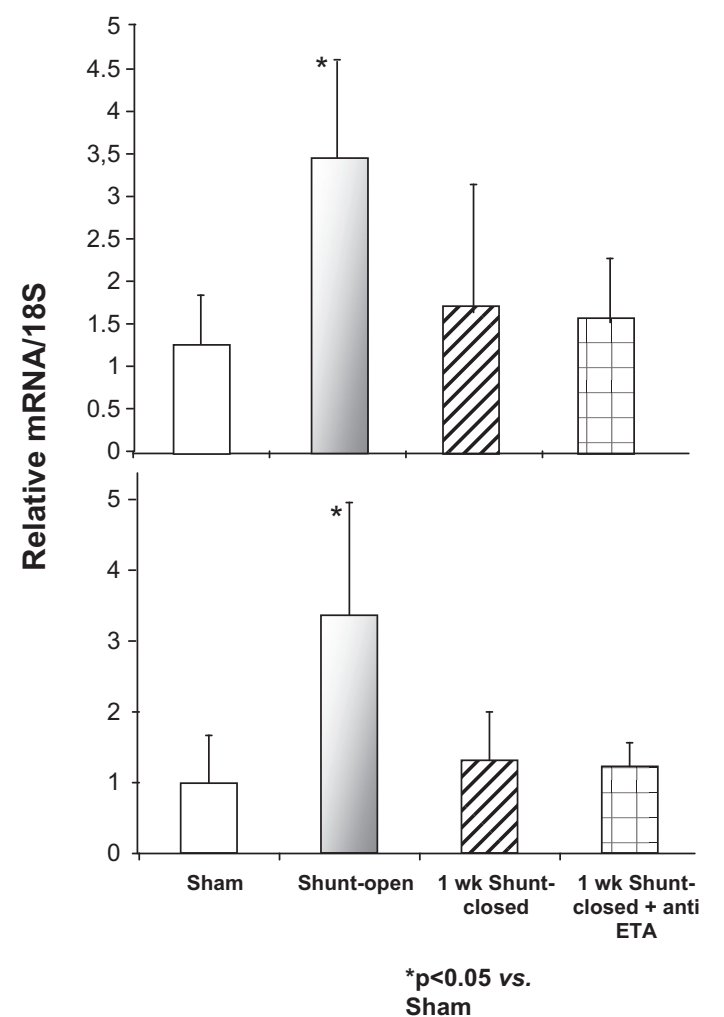

ANG-1

FIGURE 5. Quantification of angiopoietin-1 (Ang-1) and Tie 2 mRNA levels in lung parenchyma from the sham, high-flow, flow-correction, and flow-correction plus anti-ETA groups. High blood flow in the lungs increased the expression of angiopoietin-1 and Tie 2 mRNAs. Shunt closure with or without anti-ETA reversed the overexpression of these genes. ETA, Endothelin receptor type A.

reversal of distal artery medial hypertrophy. When the selective ETA antagonist TBC3711 was used in addition to flow correction, reversal of the flow-induced alterations was accelerated. This ETA antagonist may hold promise for improving post-PTE outcomes in patients with CTEPH who have high PVR values, most notably those with moderate proximal occlusion.

We are grateful to Encysive Pharmaceuticals for donating the TBC3711 used in this study.

\section{References}

1. Riedel M, Stanek V, Widimsky J, Prerovsky I. Long-term follow-up of patients with pulmonary thromboembolism. Late prognosis and evolution of hemodynamic and respiratory data. Chest. 1982;81:151-8.

2. Jamieson SW, Kapelanski DP, Sakakibara N, Manecke GR, Thistlethwaite PA, Kerr KM, et al. Pulmonary endarterectomy: experience and lessons learned in 1,500 cases. Ann Thorac Surg. 2003;76:1457-62.

3. Dartevelle P, Fadel E, Chapelier A, Macchiarini P, Cerrina J, Parquin F, et al. Angioscopic video-assisted pulmonary endarterectomy for post-embolic pulmonary hypertension. Eur J Cardiothorac Surg. 1999;16:38-43.

4. Hartz RS, Byrne JG, Levitsky S, Park J, Rich S. Predictors of mortality in pulmonary thromboendarterectomy. Ann Thorac Surg. 1996;62:1255-9.

5. Condliffe R, Kiely DG, Gibbs JS, Corris PA, Peacock AJ, Jenkins DP, et al. Improved outcomes in medically and surgically treated chronic thromboembolic pulmonary hypertension. Am J Respir Crit Care Med. 2008;177:1122-7. 
6. Dartevelle P, Fadel E, Mussot S, Chapelier A, Hervé P, de Perrot M, et al. Chronic thromboembolic pulmonary hypertension. Eur Respir J. 2004;23:637-48.

7. Moser KM, Bloor CM. Pulmonary vascular lesions occurring in patients with chronic major vessel thromboembolic pulmonary hypertension. Chest. 1993; 103:685-92.

8. Azarian R, Wartski M, Collignon MA, Parent F, Hervé P, Sors H, et al. Lung perfusion scans and hemodynamics in acute and chronic pulmonary embolism. J Nucl Med. 1997;38:980-3.

9. Yi ES, Kim H, Ahn H, Strother J, Morris T, Masliah E, et al. Distribution of obstructive intimal lesions and their cellular phenotypes in chronic pulmonary hypertension. A morphometric and immunohistochemical study. Am J Respir Crit Care Med. 2000;162(4 Pt 1):1577-86.

10. Hoeper MM, Mayer E, Simonneau G, Rubin LJ. Chronic thromboembolic pulmonary hypertension. Circulation. 2006;113:2011-20.

11. Egermayer P, Peacock AJ. Is pulmonary embolism a common cause of chronic pulmonary hypertension? Limitations of the embolic hypothesis. Eur Respir J. 2000; $15: 440-8$

12. Moser KM, Braunwald NS. Successful surgical intervention in severe chronic thromboembolic pulmonary hypertension. Chest. 1973;64:29-35.

13. Peacock A, Simonneau G, Rubin L. Controversies, uncertainties and future research on the treatment of chronic thromboembolic pulmonary hypertension. Proc Am Thorac Soc. 2006;3:608-14.

14. Anderson EG, Simon G, Reid L. Primary and thromboembolic pulmonary hypertension: a quantitative pathological study. J Pathol. 1972;110:273-93.

15. Heath D, Edwards JE. The pathology of hypertensive pulmonary vascular disease; a description of six grades of structural changes in the pulmonary arteries with special reference to congenital cardiac septal defects. Circulation. 1958;18:533-47.

16. Rondelet B, Kerbaul F, Motte S, van Beneden R, Remmelink M, Brimioulle S, et al. Bosentan for the prevention of overcirculation-induced experimental pulmonary arterial hypertension. Circulation. 2003;107:1329-35.

17. Reddy VM, Wong J, Liddicoat JR, Johengen M, Chang R, Fineman JR. Altered endothelium-dependent responses in lambs with pulmonary hypertension and increased pulmonary blood flow. Am J Physiol. 1996;271:H562-70.

18. Ovadia B, Reinhartz O, Fitzgerald R, Bekker JM, Johengen MJ, Azakie A, et al. Alterations in ET-1, not nitric oxide, in 1-week-old lambs with increased pulmonary blood flow. Am J Physiol Heart Circ Physiol. 2003 284:H480-90.

19. Black SM, Fineman JR, Steinhorn RH, Bristow J, Soifer SJ. Increased endothelia NOS in lambs with increased pulmonary blood flow and pulmonary hypertension. Am J Physiol. 1998;275:H1643-51.

20. Galiè N, Kim NH. Pulmonary microvascular disease in chronic thromboembolic pulmonary hypertension. Proc Am Thorac Soc. 2006;3:571-6.

21. Mercier O, Sage E, de Perrot M, Tu L, Marcos E, Decante B, et al. Regression of flow-induced pulmonary arterial vasculopathy after flow correction in piglets. J Thorac Cardiovasc Surg. 2009;137:1538-46.

22. Wu C, Decker ER, Blok N, Bui H, You TJ, Wang J, et al. Discovery, modeling, and human pharmacokinetics of $N$-(2 acetyl-4,6-dimethylphenyl)-3-(3,4dimethylisoxazol-5-ylsulfamoyl)thiophene-2-carboxamide (TBC3711), a second generation, ETA selective, and orally bioavailable endothelin antagonist. $J$ Med Chem. 2004;47:1969-86.

23. Perreault T, Berkenbosch JW, Barrington KJ, Decker ER, Wu C, Brock TA, et al TBC3711, an ET(A) receptor antagonist, reduces neonatal hypoxia-induced pulmonary hypertension in piglets. Pediatr Res. 2001;50:374-83.

24. Bresser P, Pepke-Zaba J, Jaïs X, Humbert M, Hoeper MM. Medical therapies for chronic thromboembolic pulmonary hypertension: an evolving treatment paradigm. Proc Am Thorac Soc. 2006;3:594-600.

25. Bonderman D, Nowotny R, Skoro-Sajer N, Jakowitsch J, Adlbrecht C, Klepetko W, et al. Bosentan therapy for inoperable chronic thromboembolic pulmonary hypertension. Chest. 2005;128:2599-603.

26. Hoeper MM, Kramm T, Wilkens H, Schulze C, Schäfers HJ, Welte T, et al. Bosentan therapy for inoperable chronic thromboembolic pulmonary hypertension. Chest. 2005;128:2363-7.

27. Hughes RJ, Jais X, Bonderman D, Suntharalingam J, Humbert M, Lang I, et al The efficacy of bosentan in inoperable chronic thromboembolic pulmonary hypertension: a 1-year follow-up study. Eur Respir J. 2006;28:138-43.

28. Jaïs X, D'Armini AM, Jansa P, Torbicki A, Delcroix M, Ghofrani HA, et al. Bosentan Effects in iNopErable Forms of chronIc Thromboembolic pulmonary hypertension Study Group. Bosentan for treatment of inoperable chronic thromboembolic pulmonary hypertension: BENEFiT (Bosentan Effects in iNopErable Forms of chronic Thromboembolic pulmonary hypertension), a randomized, placebo-controlled trial. J Am Coll Cardiol. 2008;52:2127-34. 